\title{
Shoot Heterogeneity Effects on Shiraz/Richter 99 Grapevines. III. Leaf Chlorophyll Content
}

\author{
H. Cloete ${ }^{*}$, E. Archer ${ }^{2}$, V. Novello ${ }^{3}$ and J.J. Hunter ${ }^{4}$
}

(1) Department of Viticulture and Oenology, University of Stellenbosch, Stellenbosch 7600, South Africa; and CPUT, Private Bag X8, Wellington 7654, South Africa

(2) Lusan Premium Wines, PO Box 104, Stellenbosch 7599, South Africa. E-mail: earcher@distell.co.za

(3) Dipartimento di Colture Arboree, I 10095 Grugliasco TO, Italy. E-mail: vittorino.novello@unito.it

(4) ARC Infruitec-Nietvoorbij, Private Bag X5026 Stellenbosch 7599, South Africa; and Department of Viticulture and Oenology, University of Stellenbosch, Stellenbosch 7600, South Africa. E-mail: hunterk@arc.agric.za

Submitted for publication: July 2007

Accepted for publication: March 2008

Key words: Grapevine, shoot heterogeneity, physiology, chlorophyll, shoot length

\begin{abstract}
In this study, the leaf chlorophyll content of normally developed and underdeveloped shoots was compared in an attempt to quantify the effect of shoot heterogeneity in a Shiraz/Richter 99 vineyard, located in the Stellenbosch area of the Western Cape, South Africa. Comparisons are also made between normally developed and underdeveloped shoots from shaded and well-exposed canopies. No positive correlation was found between the photosynthetic activity and the chlorophyll concentration of the leaves at five weeks after véraison. Equal amounts of chlorophyll per $\mathrm{cm}^{2}$ and a non-significant difference in the assimilation rate were calculated for the leaves of normally developed and underdeveloped shoots. No significant differences were found between the shaded and well-exposed canopies. It therefore appears that it is the effective surface area per leaf or per shoot rather than the chlorophyll concentration or activity that may be responsible for any apparent difference in the photosynthetic output of the leaves from normally developed and underdeveloped shoots in shaded or well-exposed canopies.
\end{abstract}

In higher plants, the light-absorbing pigments embedded in specialised internal membranes (collectively called the thylakoid system) inside the chloroplasts consist largely of two kinds of chlorophylls, of which the content of chlorophyll $a$ is usually two to three times that of chlorophyll $b$ (Hunter, 2001, and references therein). Light promotes some reactions during chlorophyll synthesis, such as the production of delta-amino levulinic acid (ALA - the precursor of protochlorophyllide $a$ ) and the conversion of protochlorophyllide $a$ to chlorophyll $a$. The conversion of chlorophyll $a$ to chlorophyll $b$, however, is not dependent on light.

Although the synthesis of chlorophyll is dependent on light, higher chlorophyll concentrations were found in interior leaves than in peripheral, sun-exposed peach leaves (Kappel \& Flore, 1983; Marini \& Marini, 1983). For bean plants, Crookston et al. (1975) also found more light-harvesting centres in the plastids of shaded leaves than in exposed leaves. Regarding the grapevine, Hunter and Visser (1989) reported higher chlorophyll concentrations for the interior, recently matured basal leaves in the early stages of development, while maximum chlorophyll $a$ and $b$ concentrations were reached later during the growth season as the leaves were progressively situated towards the periphery of the canopy and more towards the apical part of the shoot. The variation in chlorophyll concentration of the different leaves during the growing season was ascribed to the differences in leaf age.
According to Hunter and Visser (1989), no consistent relationship exists between chlorophyll concentration and the photosynthetic activity of exterior leaves. A better relationship was found between the chlorophyll concentration and photosynthetic activity of mature, interior canopy leaves that were exposed to conditions of lower light. They further state that factors such as the source:sink relationship, feedback inhibition of photosynthesis by end products and internal resistance to $\mathrm{CO}_{2}$ transfer within the leaf probably regulate photosynthetic activity to a greater extent than chlorophyll concentration and light intensity.

The purpose of this study was to quantify the effect of shoot heterogeneity in a Shiraz/Richter 99 vineyard on the leaf chlorophyll content of normally developed and underdeveloped shoots in shaded and well-exposed canopies. Possible relationships between chlorophyll content and photosynthetic activity, as well as the effect of chlorophyll content on the assimilation rate of the leaves on normally developed and underdeveloped shoots, were investigated.

\section{MATERIALS AND METHODS}

\section{Vineyard}

A vineyard containing seven-year-old Vitis vinifera L. cv. Shiraz, clone SH1A, grafted onto Richter 99 (Vitis berlandieri x Vitis rupestris), clone RY2A, was used for this study. The vineyard is

*Corresponding author: e-mail: theronh@cput.ac.za

Acknowledgements: All research was conducted at the ARC Infruitec-Nietvoorbij, Stellenbosch, South Africa. The authors wish to thank the personnel of the viticulture and grapevine physiology laboratory of the ARC Infruitec-Nietvoorbij, Stellenbosch, for technical assistance. The authors also wish to thank Dr Kidd of the University of Stellenbosch for the statistical analyses. 
situated on the experimental farm of the Agricultural Research Council (ARC) Infruitec-Nietvoorbij near Stellenbosch in the Western Cape (Mediterranean climate). The vines are spaced $2.75 \mathrm{~m} \times 1.5 \mathrm{~m}$ on a Glenrosa soil with a western aspect $\left(26^{\circ}\right.$ slope) and trained onto a seven-wire lengthened Perold trellising system with movable canopy wires (VSP). Rows were orientated in a north-south direction.

Micro-sprinkler irrigation was applied at the pea-size berry and véraison stages. Pest and disease control was applied during the growth season according to the standard programme of the ARC.

\section{Experimental design}

The experiment comprised a completely randomised $2 \times 2$ factorial design. The two factors were: 1) the degree of canopy exposure (shaded and well exposed) and 2) the degree of shoot development (normal and underdeveloped).

Shaded and well-exposed canopies were created randomly in vines throughout the vineyard block. Only shoot positioning and topping were done to obtain shaded canopies, while additional suckering and leaf thinning (at berry set and pea-size berry on the basal half of the canopy/shoot) were applied to create wellexposed vines. Normally developed and underdeveloped shoots were selected on the basis of their comparative length and level of lignification at véraison. The average length of normally developed shoots was $105 \mathrm{~cm}$ to $115 \mathrm{~cm}$, while the underdeveloped shoots were approximately $50 \mathrm{~cm}$ in length (Cloete et al., 2006). There were three replications for each of the four treatment combinations.

\section{Determinations of chlorophyll and photosynthesis}

The chlorophyll content of the leaves was determined according to the method described in Hunter and Visser (1989), using a LKB Biochrom Utrospec spectrophotometer (II E) and $2 \mathrm{~mm}$ quartz cells.

The equations used for calculating the chlorophyll concentration were as follows:

$$
\begin{aligned}
\text { Chlorophyll } a & =\left(0.0127 \mathrm{~A}_{663}-0.00269 \mathrm{~A}_{645}\right) \times 20000 \times 5 \\
& =\mu \mathrm{g} / \mathrm{g} \text { fresh leaf mass } \\
\text { Chlorophyll } b & =\left(0.0229 \mathrm{~A}_{645}-0.00468 \mathrm{~A}_{663}\right) \times 20000 \times 5 \\
& =\mu \mathrm{g} / \mathrm{g} \text { fresh leaf mass } \\
\text { Total chlorophyll } & =\left(0.0202 \mathrm{~A}_{645}+0.00802 \mathrm{~A}_{663}\right) \times 20000 \times 5 \\
& =\mu \mathrm{g} / \mathrm{g} \text { fresh leaf mass }
\end{aligned}
$$

The possible effect of leaf age on the leaf chlorophyll content was minimised by combining all the primary leaves on five shoots per treatment replicate when determining the chlorophyll concentration. Thus, it was primarily the effect of canopy exposure and shoot development on chlorophyll content that was determined.

The chlorophyll concentration $(\mu \mathrm{g} / \mathrm{g})$ of the fresh leaves was measured five weeks after véraison in 2002 and 2003. The chlorophyll content per unit leaf area $\left(\mu \mathrm{g} / \mathrm{cm}^{2}\right)$ and the assimilation rate $(\mu \mathrm{mol} \mathrm{CO} / \mu \mathrm{g}$ chlorophyll/h) were only calculated in 2003 . Leaf areas were measured with a LICOR LI-3100 area meter (Lincoln, Nebraska, USA). The assimilation rate was obtained by dividing the photosynthetic rate (measured with an ADC portable photosynthesis meter, Analytical Development Co., England, as described by Hunter \& Visser, 1988) by the total chlorophyll per unit of leaf area. Photosynthetic measurements were taken at
10:00 on a scheduled day (five weeks after véraison). Sun leaves, situated basally on a shoot (first three leaves above the clusters), were measured in all cases. During the measurement, care was taken not to change the orientation of the leaves relative to the sun in order to maintain the exposure to photosynthetic photon flux density (PPFD). Three leaves were measured per replicate.

\section{Statistical analyses}

Non-parametric bootstrap analyses were used when they proved to be more practical than factorial ANOVA. The significance of the results was evaluated using $95 \%$ confidence intervals. During the interpretation of the figures, differences were considered significant when no overlapping of the $95 \%$ confidence intervals occurred.

\section{RESULTS AND DISCUSSION}

Higher concentrations of chlorophyll $a$ (Fig. 1), chlorophyll $b$ (Fig. 2) and total chlorophyll ( $\mu \mathrm{g}^{\mathrm{g}} \mathrm{g}^{-1}$ fresh leaf mass) (Fig. 3) were found in the primary leaves of the underdeveloped shoots compared to the normal shoots in both years of study. This was attributed to the significantly lower PPFD received by the un-

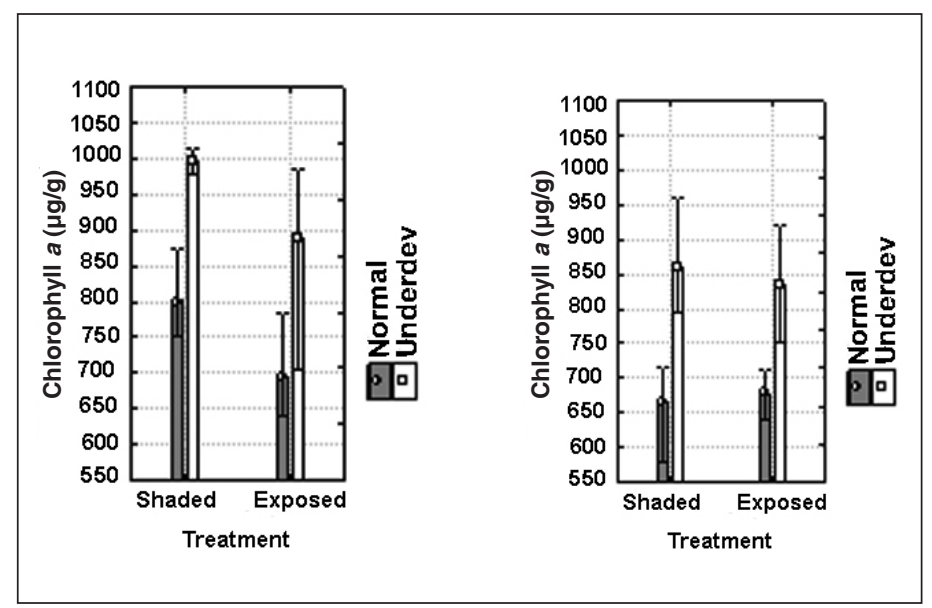

FIGURE 1

Chlorophyll $a$ concentration of primary leaves from normally developed and underdeveloped shoots in shaded and well-exposed canopies measured five weeks after véraison. A: 2002, B: 2003. Error bars indicate 95\% confidence intervals (bootstrap analysis).

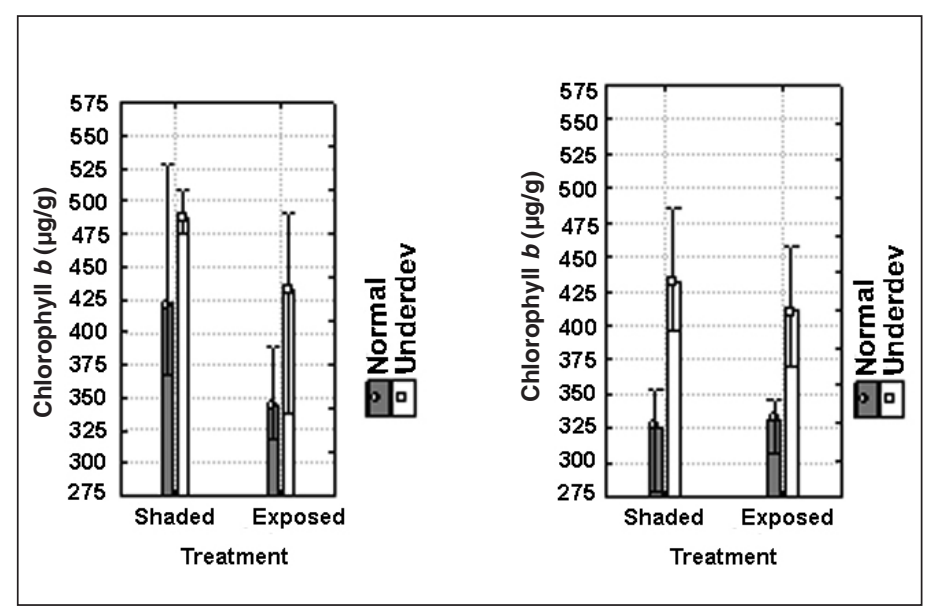

FIGURE 2

Chlorophyll $b$ concentration of primary leaves from normally developed and underdeveloped shoots in shaded and well-exposed canopies measured five weeks after véraison. A: 2002, B: 2003. Error bars indicate 95\% confidence intervals (bootstrap analysis). 


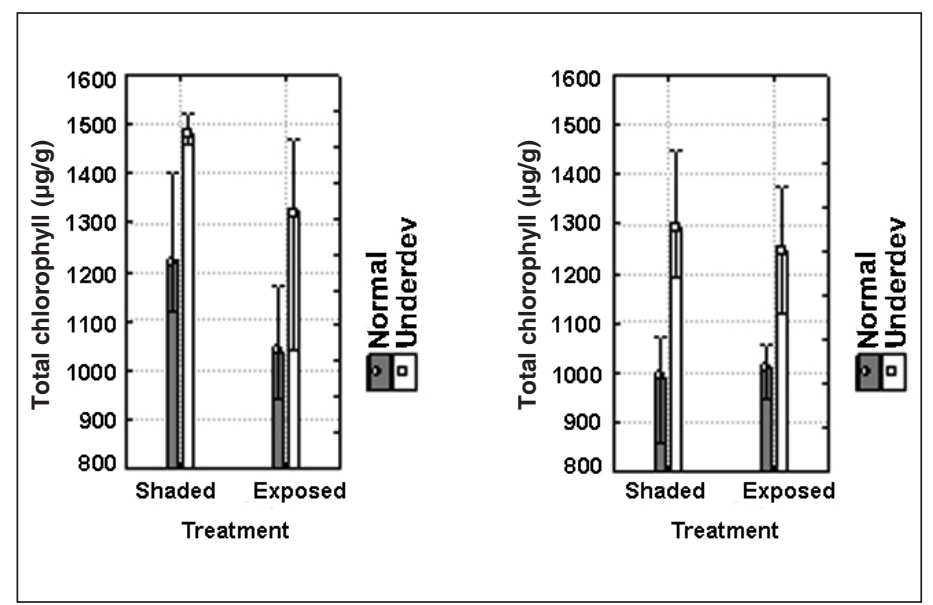

FIGURE 3

Total chlorophyll of primary leaves from normally developed and underdeveloped shoots in shaded and well-exposed canopies measured five weeks after véraison. A: 2002, B: 2003. Error bars indicate $95 \%$ confidence intervals (bootstrap analysis).

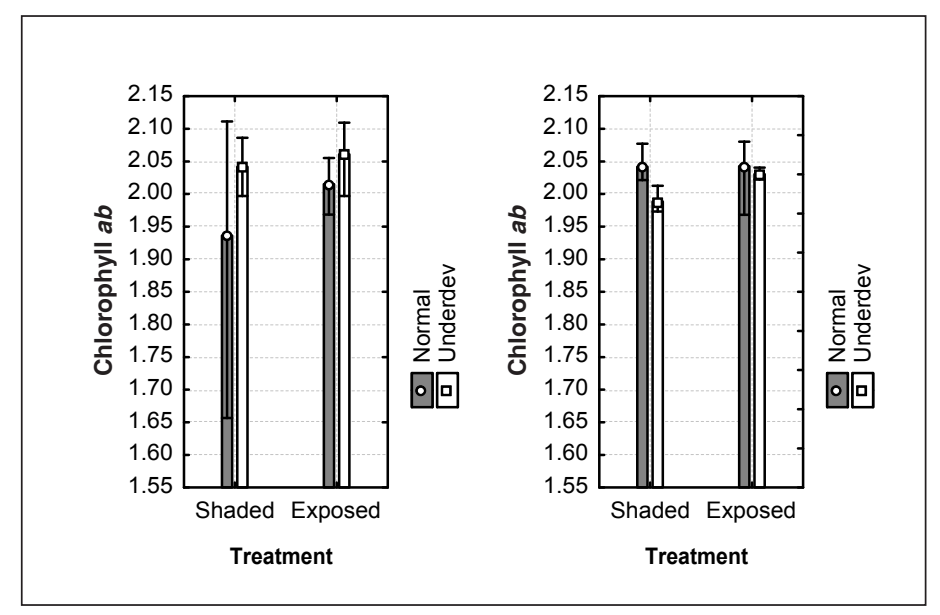

FIGURE 4

Ratio of chlorophyll $a$ to chlorophyll $b$ in primary leaves from normally developed and underdeveloped shoots in shaded and well-exposed canopies measured five weeks after véraison. A: 2002, B: 2003. Error bars indicate $95 \%$ confidence intervals (bootstrap analysis).

\section{TABLE 1}

Assimilation rate of primary leaves from normally developed and underdeveloped shoots in shaded and well-exposed canopies measured five weeks after véraison in 2003.

\begin{tabular}{ccc}
\hline Canopy exposure & Shoot development & Assimilation rate ( $\boldsymbol{\mu m o l ~ C O} / \boldsymbol{\mu g}$ chlorophyll/h) \\
\hline Shaded & Normal & $0.093^{\mathrm{a}}$ \\
Shaded & Underdeveloped $^{\mathrm{a}}$ & $0.087^{\mathrm{a}}$ \\
Well-exposed & Normal & $0.093^{\mathrm{a}}$ \\
Well-exposed & Underdeveloped $^{\mathrm{a}}$ & $0.080^{\mathrm{a}}$ \\
\hline
\end{tabular}

Values in a specific column designated by the same letter do not differ statistically on a $95 \%$ confidence level.

derdeveloped shoots at five weeks after véraison (approximately $600 \mu \mathrm{mol} / \mathrm{m}^{2} / \mathrm{s}$, compared to $1200 \mu \mathrm{mol} / \mathrm{m}^{2} / \mathrm{s}$ received by the normally developed shoots) (Cloete et al., 2008). Kappel and Flore (1983) and Marini and Marini (1983) also found that leaves under more shaded conditions tended to have higher chlorophyll per unit fresh leaf mass than those under sun-exposed conditions.

Interestingly, it seemed that the chlorophyll levels were affected differently by canopy exposure in the two years monitored. In 2002, noticeably higher levels of chlorophyll $a$ (Fig. 1a), chlorophyll $b$ (Fig. 2a) and total chlorophyll (Fig. 3a) were found in leaves from the shaded canopies, while very small differences were noticed in 2003 (Figs $1 \mathrm{~b}$ to $3 \mathrm{~b}$ ). The ratio of chlorophyll $a$ to chlorophyll $b$ was not affected by the degree of canopy exposure or shoot development in 2002, although some differences were found in 2003 (Fig. 4). In the shaded canopies, this ratio was significantly higher in the leaves of normally developed shoots, while in the case of underdeveloped shoots the ratio was higher in the well-exposed than in the shaded canopies (Fig. 4b). Sestak, cited by Hunter and Visser (1989), states that the content of chlorophyll $a$ is considered an exact characteristic of photosynthetic activity. It seems that normally developed shoots and wellexposed canopies are extremely important for the expression of the main light-absorbing pigments and the attainment of optimal photosynthetic activity in the canopy.
A higher leaf area:mass ratio and lower leaf mass were found in the underdeveloped than in the normally developed shoots (Cloete et al., 2006). Since the chlorophyll was determined on a per gram fresh leaf basis, a larger leaf area from the underdeveloped shoots than from the normally developed shoots was in fact used for each analysis. A higher leaf area:mass ratio was also found for the leaves from shaded canopies in comparison to those from well-exposed canopies (Cloete et al., 2006). Since the effective leaf area (and not the mass) in the canopy is considered an indication of the physiological potential of the canopy (Carbonneau et al., 1997), the chlorophyll content per unit leaf area was determined in 2003 (Fig. 5). Although no statistically significant difference was found between the normally developed and underdeveloped shoots or between the shaded and well-exposed canopies, it seems that the chlorophyll content per unit leaf area (and thus the light interception ability) of the leaves tended to be higher in the better exposed canopies.

The light interception, and thus the assumed physiological potential, per unit leaf area did not seem to differ between the normally developed and underdeveloped shoots. However, according to Hunter and Visser (1989) the ability of a vine leaf to intercept light is not necessarily closely related to the $\mathrm{CO}_{2}$-assimilating ability. Although the levels seemed lower in the underdeveloped shoots, no statistically significant differences in the assimilation rate $\left(\mu \mathrm{mol} \mathrm{CO}_{2} / \mu \mathrm{g}\right.$ chlorophyll/h) of the leaves were found be- 


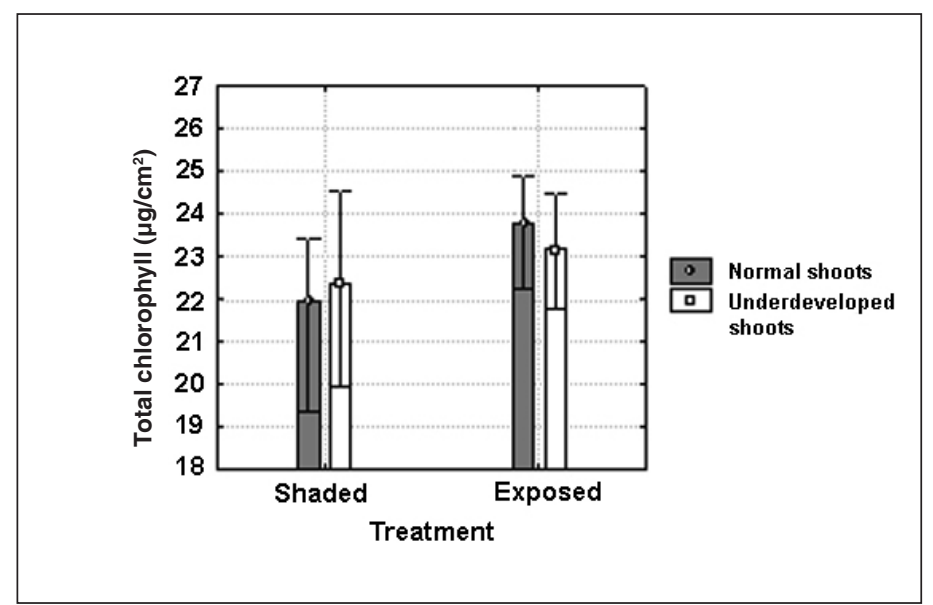

FIGURE 5

Total chlorophyll $/ \mathrm{cm}^{2}$ of primary leaves from normally developed and underdeveloped shoots in shaded and well-exposed canopies measured five weeks after véraison in 2003. Error bars indicate 95\% confidence intervals (bootstrap analysis).

tween the shaded and well-exposed canopies and between the shoot types in 2003 (Table 1).

Although higher chlorophyll concentrations $(\mu \mathrm{g} / \mathrm{g})$ were found in the underdeveloped shoots and shaded canopies (compared to normal shoots and well-exposed canopies), higher photosynthetic rates were measured in the exposed canopies and for normally developed shoots (Cloete et al., 2008) (Fig. 6). These findings are in accordance with those of Kriedemann et al. (1970) and Hunter and Visser (1989), who found no consistent relationship between the chlorophyll concentration and the photosynthetic activity of vine leaves.

According to Cloete et al. (2006), the average area per leaf and per shoot is significantly lower for underdeveloped shoots than normally developed shoots. Although the assimilation rate did not differ between the shoot types, significantly higher total chlorophyll levels per leaf (and thus also per shoot) were evident for the normal shoots. An equal amount of chlorophyll per unit leaf area and similar assimilation rates would therefore result in higher photosynthetate production in normally developed shoots.

\section{CONCLUSIONS}

Higher levels of chlorophyll $a$, chlorophyll $b$ and total chlorophyll per fresh mass were found in leaves from underdeveloped shoots compared to those from normally developed shoots. The leaf chlorophyll content therefore appears to be higher in more shaded canopies compared to better exposed canopies. No positive relationship was found between the photosynthetic activity and the chlorophyll concentration of the leaves. The limiting value of chlorophyll with regard to optimal photosynthetic activity needs to be clarified in further studies, particularly in grapevine canopies that are complex and in which source:sink relationships are dynamic during the growth season.

No statistically significant differences were found in the chlorophyll concentration per unit leaf area and the assimilation rate between normally developed and underdeveloped shoots or between

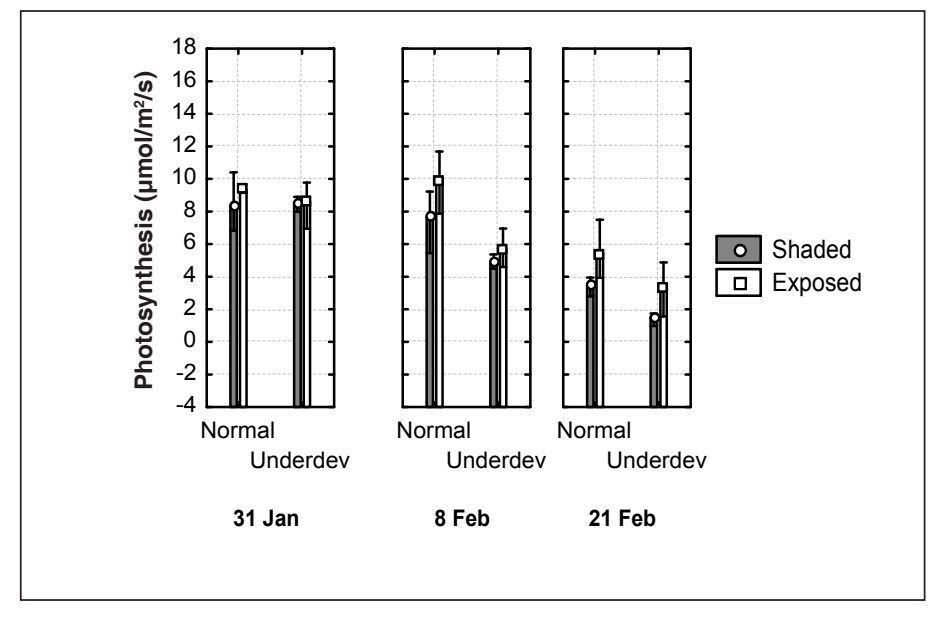

FIGURE 6

Photosynthetic rates of basal leaves from normally developed and underdeveloped shoots in shaded and well-exposed canopies measured in the second, third and fifth week after véraison. Error bars indicate 95\% confidence intervals (bootstrap analysis).

shaded and well-exposed canopies. It is argued that the effective area per leaf or per shoot probably plays a more important role than chlorophyll content per se in photosynthetate production by normally developed and underdeveloped shoots in both shaded and well-exposed canopies.

Therefore, based on the measured photosynthetic activity as well as the total expected photosynthetate production per leaf or shoot, canopy management practices that induce well-exposed canopies, together with normally developed, uniformly distributed shoots, appear very important in order to realise the full potential of grapevines.

\section{LITERATURE CITED}

Carbonneau, A., Lebon, E., Mabrouk, H. \& Sinoquet, H., 1997. Interactions: canopy shape $\times$ vigour level: consequences on architecture and microclimate of the grapevine. Acta Hort. 526, 91-105.

Cloete, H., Archer, E. \& Hunter, J.J., 2006. Shoot heterogeneity effects on Shiraz/ Richter 99 grapevines. I. Vegetative growth. S. Afr. J. Enol. Vitic. 27, 68-75.

Cloete, H., Archer, E., Novello, V. \& Hunter, J.J., 2008. Shoot heterogeneity effects on Shiraz/Richter 99 grapevines. II. Physiological activity. S. Afr. J. Enol. Vitic. 29, 1-8.

Crookston, R.K., Treharne, K.J., Ludford, P. \& Ozbun, J.L., 1975. Response of beans to shading. Crop Science 15, 412-416.

Hunter, J.J., 2001. Grapevine physiology. Private Bag X5026, Stellenbosch, 7599. E-mail hunterk@arc.agric.za.

Hunter, J.J. \& Visser, J.H., 1989. The effect of partial defoliation, leaf position and developmental stage of the vine on leaf chlorophyll concentration in relation to the photosynthetic activity and light intensity in the canopy of Vitis vinifera L. cv. Cabernet Sauvignon. S. Afr. J. Enol. Vitic. 10, 67-73.

Kappel, F. \& Flore, J.A., 1983. Effect of shade on photosynthesis, specific leaf weight, leaf chlorophyll content, and morphology of young peach trees. J. Amer. Soc. Hort. Sci. 108, 541-544.

Kriedemann, P.E., Kliewer, W.M. \& Harris, J.M., 1970. Leaf age and photosynthesis in Vitis vinifera L. Vitis 9, 97-104

Marini, R.P. \& Marini, M.C., 1983. Seasonal changes in specific leaf weight, net photosynthesis, and chlorophyll content of peach leaves as affected by light penetration and canopy position. J. Amer. Soc. Hort. Sci. 108, 600-605. 


\title{
Effect of Oxygenation During Maturation on Phenolic Composition, Total Antioxidant Capacity, Colour and Sensory Quality of Pinotage Wine
}

D. de Beer ${ }^{1 *}$, E. Joubert ${ }^{1,2}$, J. Marais ${ }^{1}$ and M. Manley ${ }^{2}$

(1) Post-Harvest and Wine Technology Division, ARC Infruitec-Nietvoorbij, Stellenbosch 7600, South Africa

(2) Department of Food Science, Stellenbosch University, Private Bag X1, 7602 Matieland (Stellenbosch), South Africa

Submitted for publication: August 2007

Accepted for publication: October 2007

Key words: Antioxidants, free radical scavenging, oxygenation, phenolic compounds

\begin{abstract}
The effect of oxygenation on the phenolic composition, total antioxidant capacity (TAC), colour and sensory quality was investigated during the maturation of Pinotage wines. Oxygenation was carried out in discrete monthly doses at two oxygen dosages $(2.5$ and $5.0 \mathrm{mg} \mathrm{O} / \mathrm{L} / \mathrm{month})$ for zero, two, four and six months. Oxygenation at the lower dosage for two months had beneficial effects on the colour and sensory quality of Pinotage wine. The higher oxygen dosage (all times) and longer times (all dosages) had a substantial detrimental effect on the overall sensory quality of the wine. A decrease in the TAC of the wine was observed for all the treatment combinations, despite increased concentrations of gallic acid. During the following harvest, a modified oxygenation treatment, entailing $1.0 \mathrm{mg} \mathrm{O}_{2} / \mathrm{L}$ in discrete doses every two weeks for two months, was tested. It had little effect on the wine phenolic composition and was not detrimental to the TAC of the wine. The modified oxygenation protocol significantly reduced the berry/ plum intensity of the Pinotage wine without negatively affecting the overall sensory quality. Oxygen addition on a continuous basis may also be less detrimental to the TAC of the wine and provide improved sensory quality.
\end{abstract}

Maturation is an important phase in the production of quality red wines, as it leads to increased colour stability and improved taste and quality in red wines. Oak barrels are generally used, but alternative oak sources, used in old barrels or stainless steel tanks, together with oxygenation, have recently increased the options available to the winemaker.

Important changes in phenolic composition during maturation involve condensation reactions of anthocyanins with flavan-3-ols to form oligomeric and polymeric phenolic compounds, leading to stabilised colour (Timberlake \& Bridle, 1976; Singleton, 1987). The main aim of the oxygenation of red wine during the maturation phase is to accelerate this colour stabilisation. In the presence of oxygen, ethanol is oxidised to acetaldehyde (Wildenradt \& Singleton, 1974), which contributes to the formation of ethyllinked anthocyanin-flavan-3-ol condensation products (Atanasova et al., 2002). Ingress of small amounts of oxygen during maturation in oak barrels also contributes to this phenomenon (Singleton, 1987). During oxygenation, however, the amount of oxygen delivered to a wine can be controlled. Oxygen can be applied continuously (Atanasova et al., 2002; Du Toit et al., 2006) or in discrete doses (Castellari et al., 2000).

Since oxygenation affects the phenolic composition of the wine, especially with regard to polymerisation, it is possible that the total antioxidant capacity (TAC) of the wine will also be affected. A change in TAC during maturation is most likely to be negative. Some reactions of phenolic compounds during pre-bottling maturation are expected to be similar to those that occur during bottle maturation, which has been shown to decrease the TAC of Pinotage and Cabernet Sauvignon wines (De Beer et al., 2005).
To date, no reports have been published on the effects of oxygenation on the antioxidant capacity of red wines. In order to produce wines with optimal TAC, the effect of oxygenation on TAC should be taken into account. The aim of this study was to investigate the effect of oxygenation during maturation on the phenolic composition, TAC, colour and sensory quality of Pinotage wines.

\section{MATERIALS AND METHODS}

\section{Oxygenation treatments}

A Pinotage wine was produced from grapes (Vitis vinifera L. cv. Pinotage) harvested at $\sim 23$ to $24^{\circ} \mathrm{B}$ at Nietvoorbij (Stellenbosch, South Africa) during March 2003 and March 2004. Winemaking was carried out at the experimental cellar of ARC InfruitecNietvoorbij (Stellenbosch, South Africa) according to the standard winemaking protocol as described by De Beer et al. (2006), with no wood contact and no malolactic fermentation. Instead of bottling after cold stabilisation and filtering, the 2003 wine was divided into 30 closed stainless steel containers $(20 \mathrm{~L})$, with three containers for each of the treatment and time combinations. The oxygenation treatments consisted of a control (wine before oxygenation), no oxygenation ( $0 \mathrm{mg} \mathrm{O} / \mathrm{L} /$ month), low-level oxygenation (2.5 $\left.\mathrm{mg} \mathrm{O}_{2} / \mathrm{L} / \mathrm{month}\right)$ and high-level oxygenation $(5.0 \mathrm{mg}$ $\mathrm{O}_{2} / \mathrm{L} /$ month) for two, four and six months (Fig. 1). Oxygenation was carried out in discrete doses at monthly intervals. The control wines were bottled when the oxygenation treatments commenced. The wine used in 2004 was divided into six containers, with three containers for each of the two treatments, which consisted of a control (no oxygenation; bottled directly after cold stabilisation and filtering) and an oxygenation treatment ( $\left.1.0 \mathrm{mg} \mathrm{O}_{2} / \mathrm{L}\right)$ applied 
every two weeks for two months. During the oxygenation treatments, wines were stored at $15^{\circ} \mathrm{C}$. Oxygenation consisted of introducing compressed medical air (Afrox, Johannesburg, South Africa) into the wine using a gas diffuser until wine oxygen concentrations reached the desired level. The dissolved oxygen concentration was measured using an Oxi 330 Set oxygen analyser with a CellOx 325 probe (WTW, Weilheim, Germany). One week after each oxygenation treatment, the $\mathrm{SO}_{2}$ concentration was adjusted to $25 \mathrm{mg} / \mathrm{L}$ free $\mathrm{SO}_{2}$. The wines were bottled two weeks after the completion of each oxygenation treatment. The wines were stored at $15^{\circ} \mathrm{C}$ until the wine treated for six months had been bottled, and thereafter they were stored at $25^{\circ} \mathrm{C}$ until sampling and sensory analysis. Sampling occurred at the same time as sensory analysis, which was two months after the wine from the last treatment had been bottled. Aliquots from each treatment and time combination were frozen at $-20^{\circ} \mathrm{C}$ to prevent further phenolic changes until the analyses could be carried out. Samples were analysed immediately after defrosting.

\section{Chemicals and phenolic reference standards}

2,2'-Azino-di-(3-ethylbenzo-thialozine-sulphonic acid) (ABTS) was obtained from Boehringer Mannheim GmbH (Mannheim, Germany) and HPLC-grade acetonitrile and phosphoric acid were obtained from Riedel-de Häen (Seelze, Germany) and Fluka (Buchs, Switzerland) respectively. 6-Hydroxy-2,5,7,8-tetra-methylchroman-2-carboxylic acid (Trolox) was obtained from Aldrich Chemical Co. (Gillingham, UK). Phenolic reference standards included gallic acid, (+)-catechin, (-)-epicatechin, quercetin-3-galactoside (Gal) and quercetin-3-rhamnoside (Rham) from Sigma (St Louis, MO); caffeoyltartaric acid from Chromadex (Santa Ana, CA); caffeic acid, quercetin and kaempferol from Fluka; procyanidin B1, quercetin-3-glucoside (Glc) and myricetin from Extrasynthese (Genay, France); and delphinidin-3-Glc, peonidin-3-Glc, petunidin-3Glc and malvidin-3-Glc from Polyphenols AS (Sandnes, Norway). Water used in the experiments was purified and de-ionised using a Modulab water purification system (Separations, Cape Town, South Africa), except for that used in the preparation of the HPLC mobile phases, where the de-ionised water was treated further using a Milli-Q academic water purifier (Millipore, USA).

\section{Spectrophotometric analysis of phenolic content}

The wines were subjected to spectrophotometric analysis for the determination of the major phenolic groups. Total phenol and total flavan-3-ol content was determined in triplicate using the Folin-Ciocalteau (Singleton \& Rossi, 1965) and dimethylaminocinnamaldehyde (DAC) (McMurrough \& McDowell, 1978) assays respectively. The monomeric, polymeric and total anthocyanin content was determined using a $\mathrm{pH}$ shift assay modified from that of Ribéreau-Gayon and Stonestreet (1965) as described in De Beer et al. (2003). A pH 4.9 acetate buffer was used instead of a pH 3.5 phosphate buffer. Anthocyanins were quantified as milligrams of malvidin-3-Glc equivalents/L.

\section{HPLC analysis of phenolic composition}

Individual phenolic compounds, as well as coloured and noncoloured polymers detected at 520 and $280 \mathrm{~nm}$ respectively, were quantified in duplicate using an HPLC method (Peng et al., 2002), modified and described by De Beer et al. (2006). Polymers included polymeric phenolic compounds with five or more subunits, consisting of coloured and non-coloured polymers.

\section{ABTS radical cation scavenging assay}

The total antioxidant capacity (TAC) of the wines was measured $\left(\mathrm{TAC}_{\mathrm{M}}\right)$ in triplicate using the $\mathrm{ABTS}^{++}$scavenging assay (Re et al., 1999). The content of individual phenolic compounds, measured by HPLC, and their experimental TEAC values (reported in De Beer et al., 2006), were used to calculate the theoretical TAC $\left(\mathrm{TAC}_{\mathrm{CAL}}\right)$. The remaining TAC $\left(\mathrm{TAC}_{\mathrm{R}}\right)$ is the difference between $\mathrm{TAC}_{\mathrm{M}}$ and $\mathrm{TAC}_{\mathrm{CAL}}$. The analysis and calculations were carried out as described in De Beer et al. (2006).

\section{Objective colour parameters}

A Colorgard System 2000 Colourimeter (BYK-Gardner, Geretsried, Germany) was used to measure the objective colour parameters of the undiluted wines from all vintages in transmittance mode in an optical cell with a fixed path length of $5 \mathrm{~mm}$. The colorimeter was calibrated before use with a non-diffusing black reflectance standard (BYK-Gardner, Geretsried, Germany). Objective colour measurements were performed $<1 \mathrm{~h}$ after opening a wine bottle to minimise colour changes. The CIELab parameters, namely a* (red/green

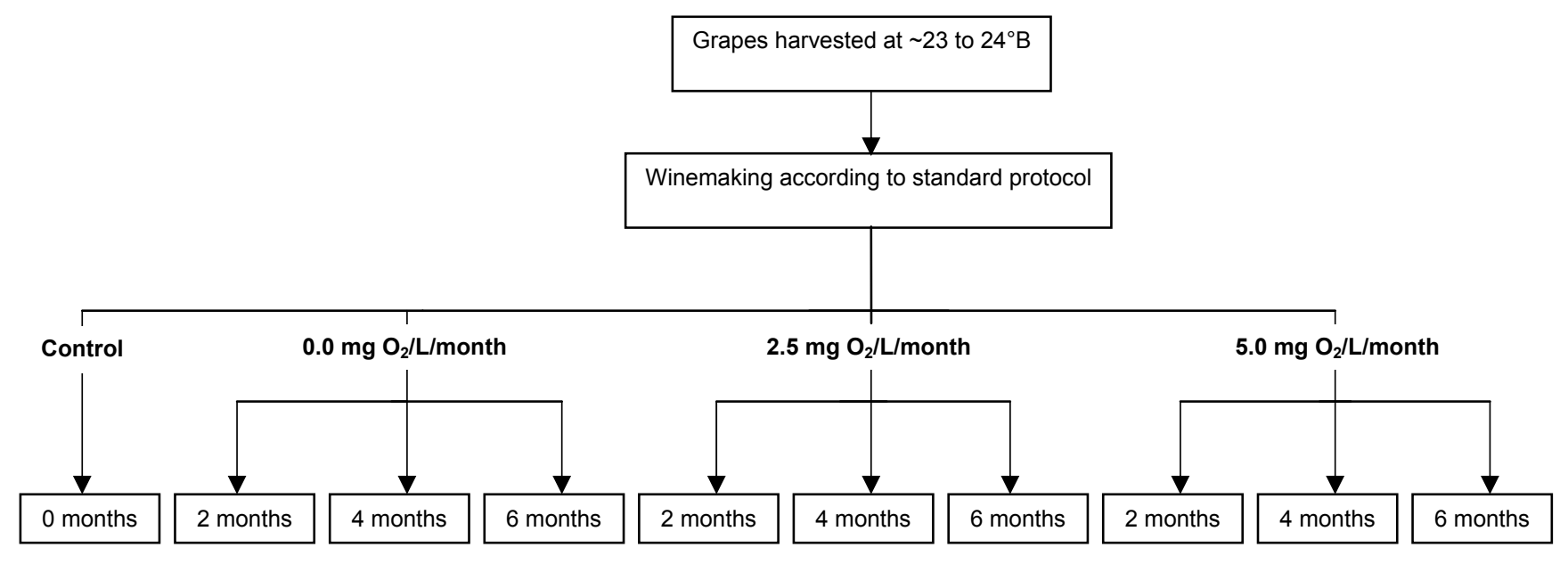

FIGURE 1

Scheme of oxygenation treatments of Pinotage wine. 
chromaticity), b* (yellow/blue chromaticity) and L* (lightness), were measured using the CIE 1931 standard colorimetric observer under illuminant $\mathrm{C}$ (geometry is $45^{\circ}$ illumination and $0^{\circ}$ viewing). The $\mathrm{h}^{*}$ (hue angle; ${ }^{\circ}$ ) and $\mathrm{C}^{*}$ (chroma) were calculated as follows:

$$
\begin{aligned}
& h^{*}=\tan ^{1}\left(b^{*} / a^{*}\right) \\
& c^{*}=\left[\left(a^{*}\right)^{2}+\left(b^{*}\right)^{2}\right]^{1 / 2}
\end{aligned}
$$

Names for hues were adapted from Gonnet (1999), based on the $h^{*}$ values. Hue angle values of $0^{\circ}, 7.5^{\circ}, 15^{\circ}, 22.5^{\circ}, 30^{\circ}, 37.5^{\circ}$ and $45^{\circ}$ correspond to magenta, red-magenta, magenta-red, red, orange-red, red-orange and orange respectively.

\section{Sensory analysis}

The wines were evaluated two months after the last treated wines had been bottled, i.e. eight months after fermentation, for colour acceptability, berry/plum intensity, astringency, fullness and overall wine quality. The evaluation was done by a panel of six experienced judges, comprising winemakers from the industry. Wines were presented in random order. Evaluation was done by making a mark on an unstructured $10 \mathrm{~cm}$ line scale. The scales were anchored at both ends by the terms "unacceptable" and "excellent" for colour acceptability and overall wine quality, "low" and "high" for berry/plum intensity and astringency, and "thin" and "full" for fullness. Judges were calibrated before the sensory analysis by reaching consensus on the scores for two sample wines.

\section{Statistical analysis}

Analysis of variance was performed on the means of triplicate or duplicate samples of each oxygenation treatment and time combination to determine whether significant differences occurred. The Student $t$-LSD test $(\mathrm{p} \leq 0.05)$ was used to determine whether the means differed significantly. Analysis of variance and difference testing were done using the SAS version 8 software package (SAS Institute Inc., Cary, NC).

\section{RESULTS}

\section{Phenolic composition of the wines from 2003}

The phenolic composition of the non-oxygenated wine remained largely unchanged during the six-month period (Fig. 2), with only its total monomer content (HPLC) significantly higher than that in the oxygenated treatments after six months (Fig. 2A). Oxygenation caused a significant decrease in the total monomer (HPLC) and total phenol (Fig. 2B) content of the wine. Higher losses were observed at $5.0 \mathrm{mg} \mathrm{O} / \mathrm{L} / \mathrm{month}$ than at $2.5 \mathrm{mg} \mathrm{O} / \mathrm{L} / \mathrm{month}$.

Oxygenation, on the other hand, caused a significant decrease in the monomeric anthocyanin content, as measured using both the HPLC (Fig. 2C) and pH shift (Fig. 2D) methods. This decrease over the treatment period occurred at both oxygenation levels, but was more pronounced at $5.0 \mathrm{mg} \mathrm{O} / \mathrm{L} / \mathrm{month}$ (Fig. $2 \mathrm{C}$ to $\mathrm{L}$ ). The same trend was observed for the content of all the individual anthocyanins, except for the vitisin A content (Fig. 2E to $\mathrm{N})$. The vitisin A content increased significantly with oxygenation at $2.5 \mathrm{mg} \mathrm{O} / \mathrm{L} /$ month for two months and oxygenation at $5.0 \mathrm{mg}$ $\mathrm{O}_{2} / \mathrm{L} /$ month for two and four months, but after six months its content at both oxygenation levels was similar to that of the control $(p>0.05)$. Several of the anthocyanins, namely peonidin-3-Glc, delphinidin-3-Glc-Ac, petunidin-3-Glc-Ac and malvidin-3-GlcCoum, could not be detected in the wine treated for six months with $5.0 \mathrm{mg} \mathrm{O} / \mathrm{L} / \mathrm{month}$. Only the four- and six-month treatments at $5.0 \mathrm{mg} \mathrm{O} / 2 / \mathrm{L}$ onth caused a significant increase in coloured polymer content (HPLC) (Fig. 2O). On the other hand, the polymeric anthocyanin content ( $\mathrm{pH}$ shift) exhibited significantly increased concentrations when $5.0 \mathrm{mg} \mathrm{O} / \mathrm{L} /$ month was applied for all time intervals, as well as when $2.5 \mathrm{mg} \mathrm{O} / \mathrm{L} / \mathrm{month}$ was applied for four and six months (Fig. 2P).

The concentration of the total flavonol content and the content of several individual flavonols, namely an unknown flavonol, quercetin-3-Glc, quercetin-3-rhamnoside (Rham) and isorhamnetin, decreased significantly as a result of oxygenation, irrespective of the concentration (Fig. 2Q to X). The application of $5.0 \mathrm{mg} \mathrm{O}_{2} / \mathrm{L} /$ month also decreased the quercetin-3-galactoside (Gal), quercetin and kaempferol contents, with the wine treated for six months having significantly lower contents than the control wine.

The total phenolic acid (Fig. 2Y), caftaric acid (Fig. 2Z), coutaric acid (data not shown) and $p$-coumaric acid (data not shown) contents showed similar trends, i.e. no significant change in content over the six-month period. The caffeic acid content of the wine, on the other hand, decreased significantly with the application of $2.5 \mathrm{mg} \mathrm{O} / \mathrm{L} / \mathrm{month}$ for six months and with $5.0 \mathrm{mg}$ $\mathrm{O}_{2} / \mathrm{L} /$ month for four and six months (Fig. 2AA). All the oxygenated wines, except the wines oxygenated at $2.5 \mathrm{mg} \mathrm{O} / \mathrm{L} / \mathrm{month}$ for two months, had a significantly higher gallic acid content than the control (Fig. 2BB). At both oxygenation levels the gallic acid content increased significantly with oxygenation time, with the highest gallic acid content observed when $5.0 \mathrm{mg} \mathrm{O} / \mathrm{L} / \mathrm{month}$ was applied for six months.

At both oxygenation levels, but to a greater extent at $5.0 \mathrm{mg}$ $\mathrm{O}_{2} / \mathrm{L} /$ month, the total flavan-3-ol (HPLC and DAC methods), $(+)$-catechin and procyanidin B1 content of the wine decreased significantly over time (Fig. 2CC to FF). The non-coloured polymer content of the wines did not change significantly during oxygenation, irrespective of the dosage (data not shown).

\section{Antioxidant capacity of the wines from 2003}

All the wines treated with oxygen had significantly lower $\mathrm{TAC}_{\mathrm{M}}$, $\mathrm{TAC}_{\mathrm{CAL}}$ and $\mathrm{TAC}_{\mathrm{R}}$ than the non-oxygenated wines, although the period of oxygenation did not have a significant effect on the $\mathrm{TAC}_{\mathrm{M}}$ or $\mathrm{TAC}_{\mathrm{R}}$ (Fig. 3A to $\mathrm{C}$ ). The decrease in $\mathrm{TAC}_{\mathrm{CAL}}$ was, however, more pronounced for longer oxygenation periods. The $\mathrm{TAC}_{\mathrm{M}}, \mathrm{TAC}_{\mathrm{CAL}}$ and $\mathrm{TAC}_{\mathrm{R}}$ of the non-oxygenated wines did not change significantly during the oxygenation period. Substantial and significant decreases in the contribution of flavan-3-ols, flavonols and especially anthocyanins to the $\mathrm{TAC}_{\mathrm{CAL}}$ were observed for the oxygenated wines. A significant increase in contribution to the $\mathrm{TAC}_{\mathrm{CAL}}$ was observed only in the case of gallic acid (Fig. 4).

\section{Objective colour parameters of the wines from 2003}

The colour parameters of the oxygenated and non-oxygenated wines are depicted in Fig. 3D to H. The $C^{*}$ and $a^{*}$ values of both the non-oxygenated and oxygenated Pinotage wines decreased significantly during the treatment period. The decreases in $C^{*}$ and $a^{*}$ values were more pronounced for the application of $5.0 \mathrm{mg}$ $\mathrm{O}_{2} / \mathrm{L} /$ month than for $2.5 \mathrm{mg} \mathrm{O} / \mathrm{L} /$ month. Initially, oxygenation significantly increased the $h^{*}$ and $b^{*}$ values of the wines, after which they decreased. However, the final $h^{*}$ of the wines subjected to oxygenation still was significantly higher than that of the control wine. The $L^{*}$ value of the oxygenated wines decreased significantly during the six-month period, but not that of the nonoxygenated wines. 

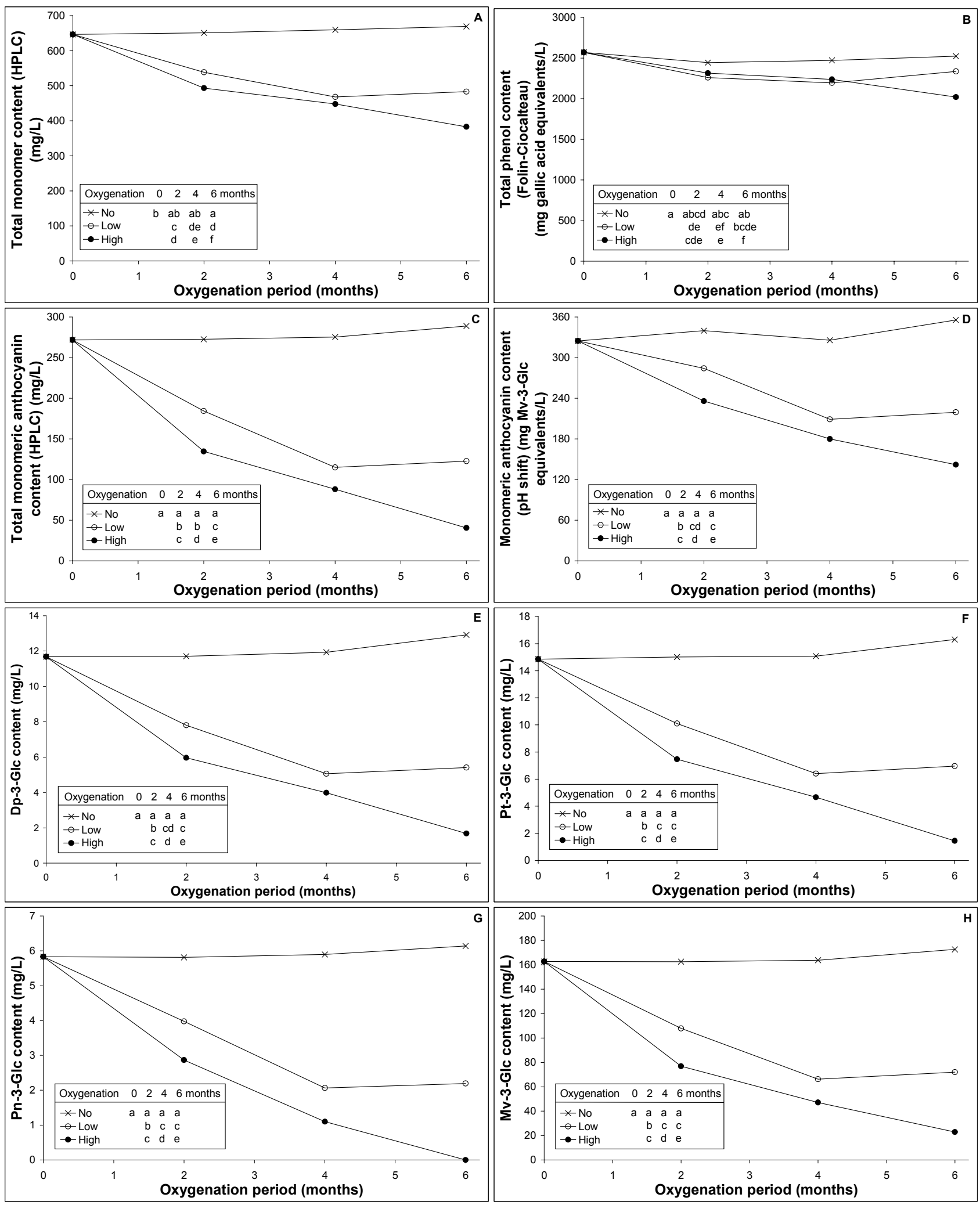

FIGURE 2

Effect of oxygenation on the phenolic composition of Pinotage wine, measured using spectrophotometric assays and HPLC [description of figure legends: no $=$ application of $0.0 \mathrm{mg} \mathrm{O} / / \mathrm{L} / \mathrm{month}$; low = application of $2.5 \mathrm{mg} \mathrm{O} / \mathrm{L} / \mathrm{month}$; high = application of $5.0 \mathrm{mg} \mathrm{O} / \mathrm{L} / \mathrm{month}$. Different letters denote significant differences (p $\leq 0.05)$ $\mathrm{Dp}=$ delphinidin; $\mathrm{Gal}=$ galactoside; $\mathrm{Glc}=$ glucoside; $\mathrm{Glc}-\mathrm{Ac}=$ acetylglucoside; $\mathrm{Glc}-\mathrm{Coum}=p$-coumaroylglucoside; $\mathrm{Mv}=$ malvidin; $\mathrm{Pn}=$ peonidin; $\mathrm{Pt}=$ petunidin;

\author{
Rham $=$ rhamnoside
}



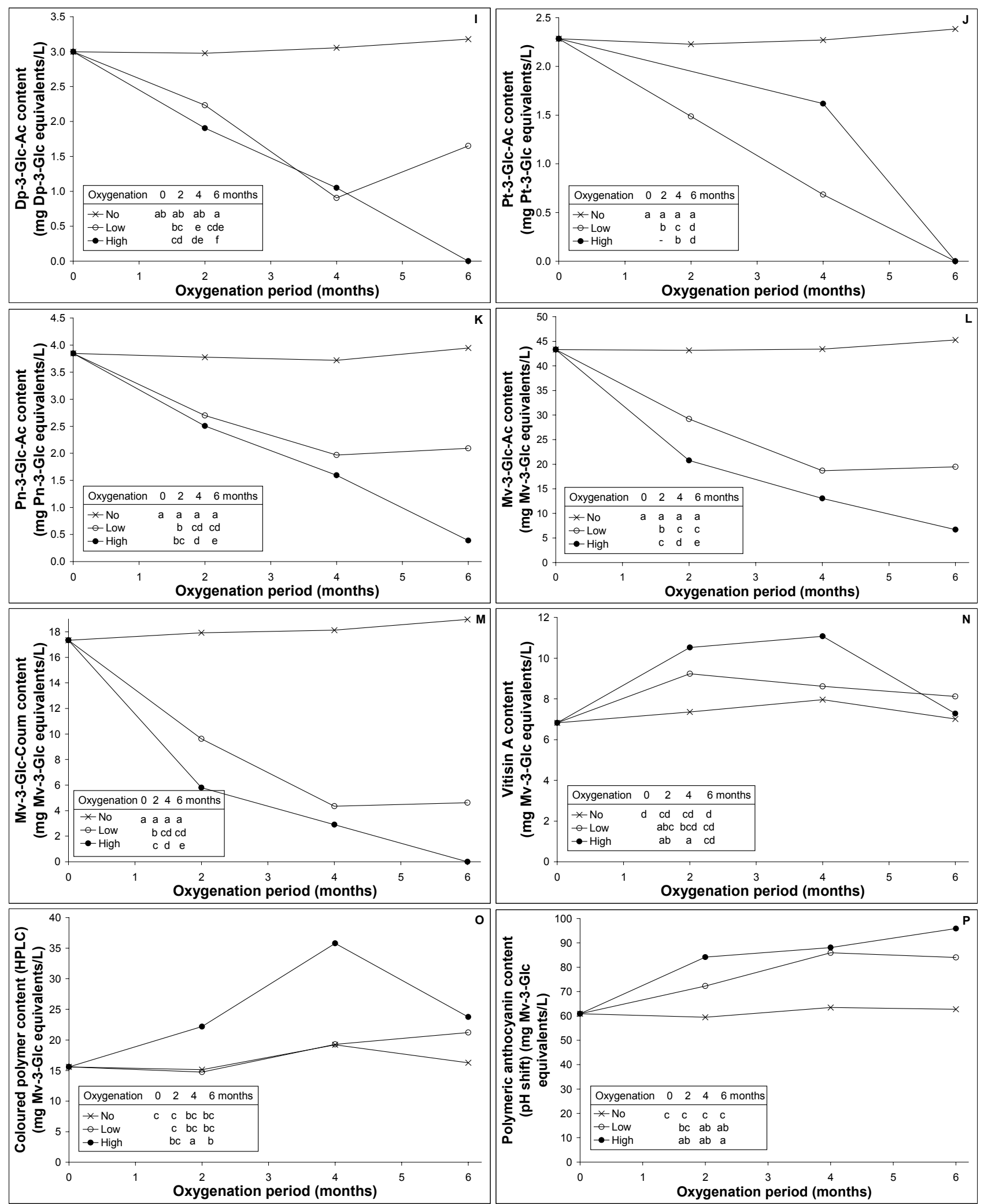

FIGURE 2 (continued)

Effect of oxygenation on the phenolic composition of Pinotage wine, measured using spectrophotometric assays and HPLC [description of figure legends: no $=$ application of $0.0 \mathrm{mg} \mathrm{O} / \mathrm{L} / \mathrm{month}$; low = application of $2.5 \mathrm{mg} \mathrm{O} / \mathrm{L} / \mathrm{month}$; high = application of $5.0 \mathrm{mg} \mathrm{O} / \mathrm{L} / \mathrm{month}$. Different letters denote significant differences ( $\mathrm{p} \leq 0.05$ ). $\mathrm{Dp}=$ delphinidin $; \mathrm{Gal}=$ galactoside Glc = glucoside; Glc-Ac = acetylglucoside $;$ Glc-Coum = $p$-coumaroylglucoside; $\mathrm{Mv}=$ malvidin $; \mathrm{Pn}=$ peonidin; $\mathrm{Pt}=$ petunidin;

Rham $=$ rhamnoside. 

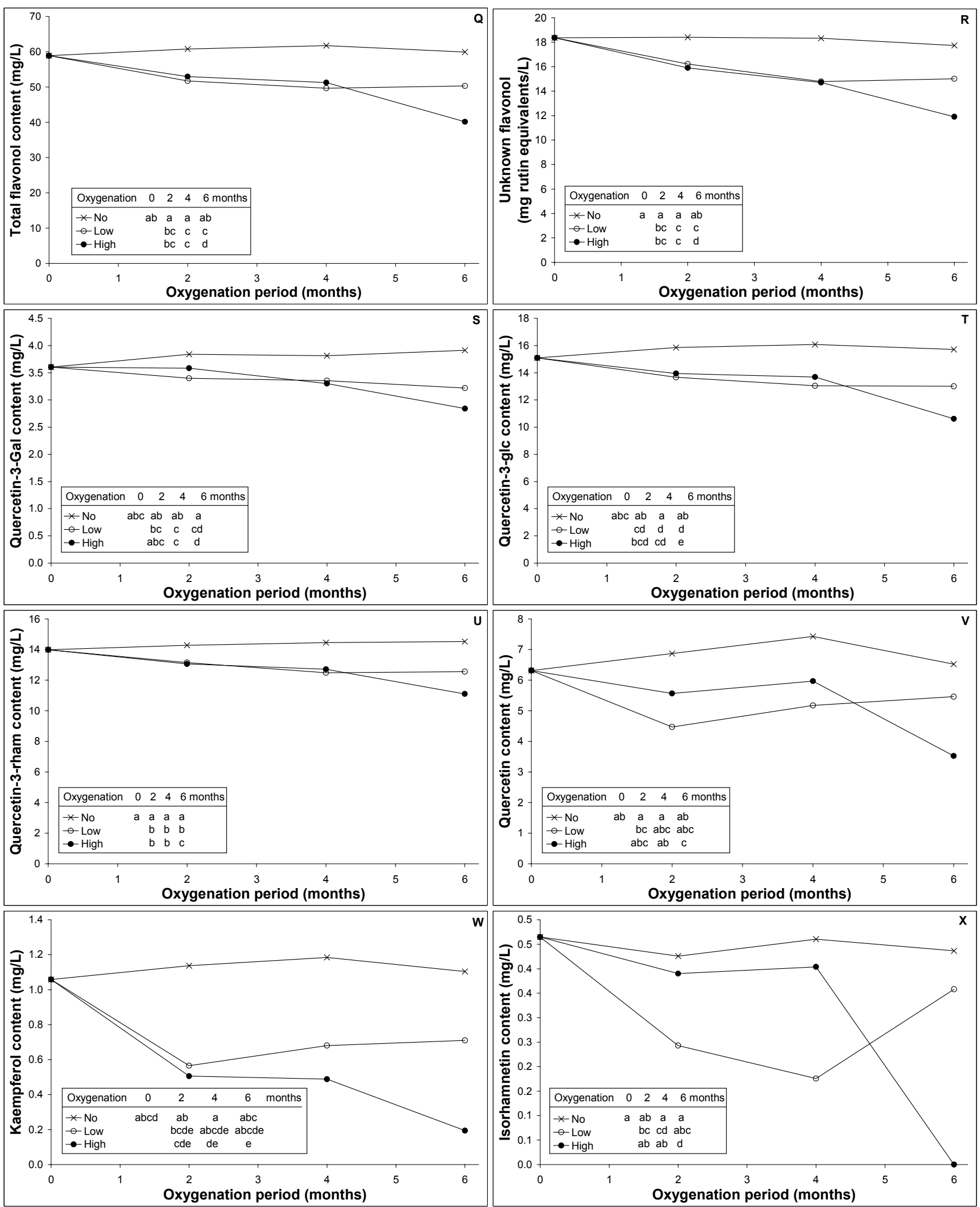

FIGURE 2 (continued)

Effect of oxygenation on the phenolic composition of Pinotage wine, measured using spectrophotometric assays and HPLC [description of figure legends: no $=$ application of $0.0 \mathrm{mg} \mathrm{O} / \mathrm{L} / \mathrm{month}$; low = application of $2.5 \mathrm{mg} \mathrm{O} / / \mathrm{L} / \mathrm{month}$; high = application of $5.0 \mathrm{mg} \mathrm{O} / / \mathrm{L} / \mathrm{month}$. Different letters denote significant differences ( $\mathrm{p} \leq 0.05$ ) $\mathrm{Dp}=$ delphinidin; $\mathrm{Gal}=$ galactoside $; \mathrm{Glc}=$ glucoside Glc-Ac = acetylglucoside; Glc-Coum = p-coumaroylglucoside; $\mathrm{Mv}=$ malvidin; $\mathrm{Pn}=$ peonidin; $\mathrm{Pt}=$ petunidin;

Rham $=$ rhamnoside. 

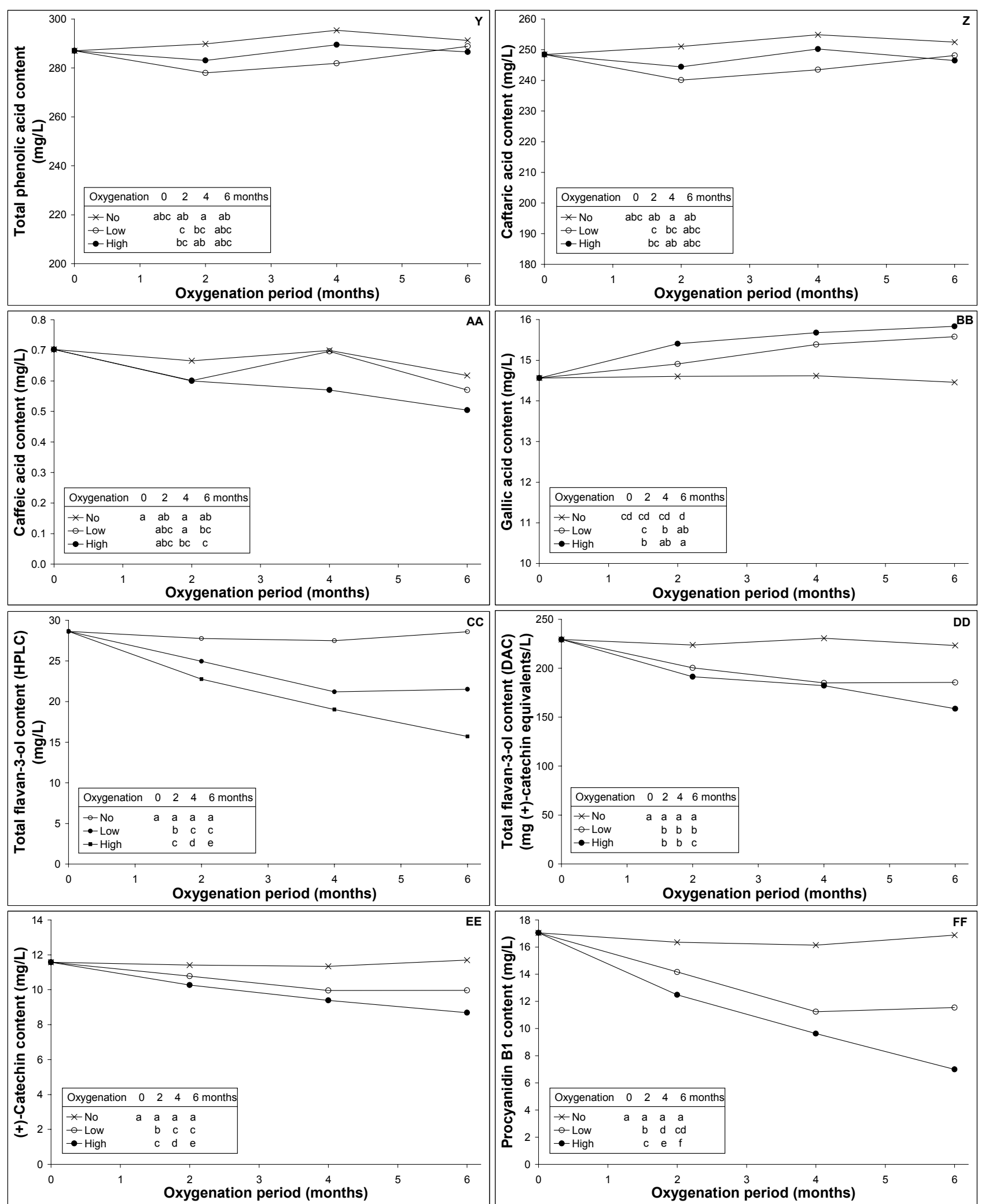

FIGURE 2 (continued)

Effect of oxygenation on the phenolic composition of Pinotage wine, measured using spectrophotometric assays and HPLC [description of figure legends: no $=$ application of $0.0 \mathrm{mg} \mathrm{O} / 2 / \mathrm{Lmonth}$; low = application of $2.5 \mathrm{mg} \mathrm{O} / \mathrm{L} / \mathrm{month}$; high = application of $5.0 \mathrm{mg} \mathrm{O} / \mathrm{L} / \mathrm{month}$. Different letters denote significant differences ( $\mathrm{p} \leq 0.05$ ) $\mathrm{Dp}=$ delphinidin $; \mathrm{Gal}=$ galactoside Glc = glucoside; Glc-Ac = acetylglucoside $;$ Glc-Coum = $p$-coumaroylglucoside; $\mathrm{Mv}=$ malvidin $; \mathrm{Pn}=$ peonidin; $\mathrm{Pt}=$ petunidin;

Rham = rhamnoside. 

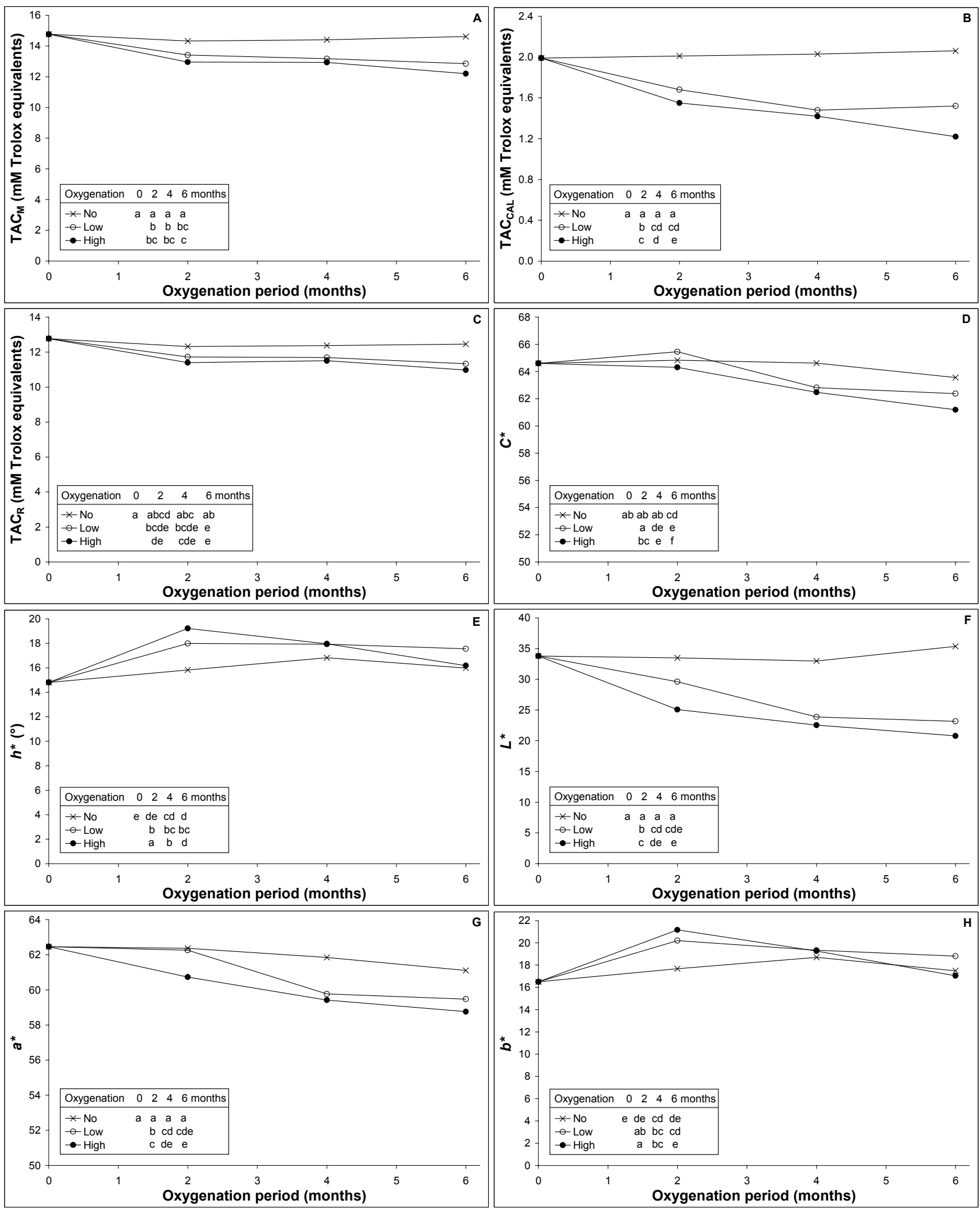

FIGURE 3

Effect of oxygenation on the total antioxidant capacity and colour of Pinotage wine. Description of figure legends: no $=$ application of 0.0 mg $\mathrm{O}_{2} / \mathrm{L} / \mathrm{month}$; low $=$ application of $2.5 \mathrm{mg} \mathrm{O} / \mathrm{L} / \mathrm{month}$; high = application of $5.0 \mathrm{mg} \mathrm{O}_{2} / \mathrm{L} / \mathrm{month}$. Different letters denote significant differences $(\mathrm{p} \leq 0.05) ; C^{*}=$ chroma; $h^{*}=$ hue angle $\left({ }^{\circ}\right) ; L^{*}=$ lightness; $a^{*}=$ red/green chromaticity; $b^{*}=$ yellow/blue chromaticity. 


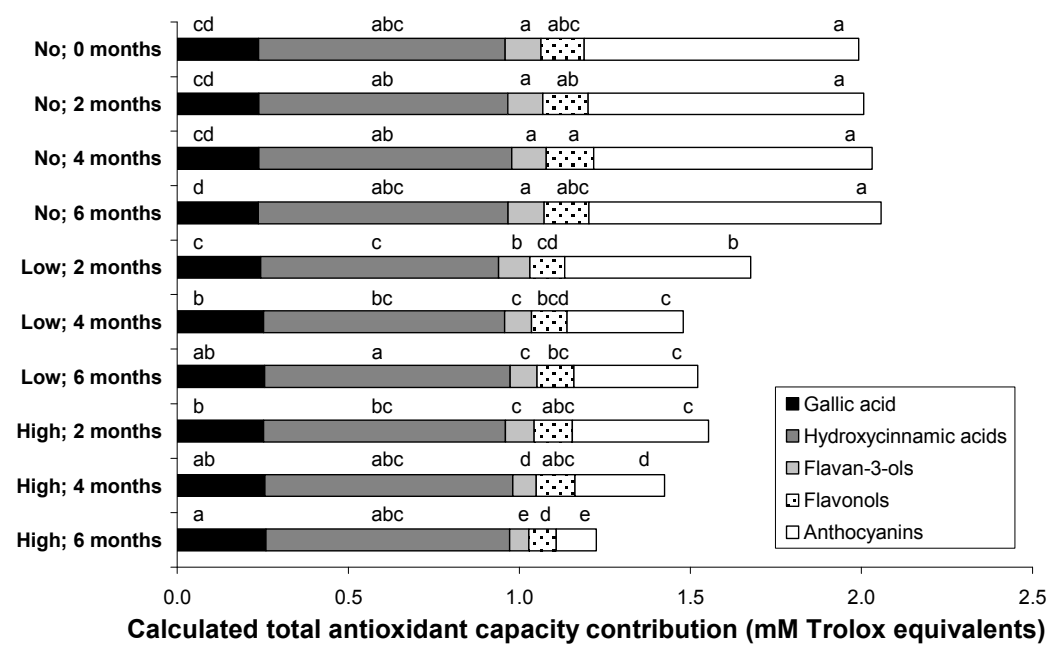

FIGURE 4

Calculated total antioxidant capacity contributions of phenolic groups for different oxygenation treatments. No $=$ application of $0.0 \mathrm{mg} \mathrm{O}_{2} / \mathrm{L} / \mathrm{month}$; low $=$ application of $2.5 \mathrm{mg} \mathrm{O} / \mathrm{L} / \mathrm{month}$; high = application of $5.0 \mathrm{mg} \mathrm{O} / \mathrm{L} / \mathrm{month}$. Different letters denote significant differences $(\mathrm{p} \leq 0.05)$.

\section{Sensory quality of the wines from 2003}

The non-oxygenated wines retained their sensory characteristics throughout the six-month period, i.e. no significant changes were observed (Fig. 5A to E). The scores for sensory colour acceptability of the oxygenated wines increased significantly, irrespective of the oxygen concentration. Berry/plum intensity scores decreased significantly with oxygenation, and this decrease was more pronounced when $5.0 \mathrm{mg} \mathrm{O} / \mathrm{L} / \mathrm{month}$ was applied. There were no significant changes in the astringency scores of the wines during oxygenation. Fullness scores were significantly higher for all wines oxygenated at $5.0 \mathrm{mg} \mathrm{O} / \mathrm{L} /$ month than for the non-oxygenated wines, while oxygenation at $2.5 \mathrm{mg} \mathrm{O}_{2} / \mathrm{L} /$ month significantly increased the fullness scores for the six-month treatment period. Considering the overall quality of the wine, only the two-month treatment at 2.5 $\mathrm{mg} \mathrm{O}_{2} / \mathrm{L} /$ month showed no significant change. Wines that received the $2.5 \mathrm{mg} \mathrm{O} / \mathrm{L} / \mathrm{month}$ treatment only gave significantly decreased overall quality scores after six months. The application of $5.0 \mathrm{mg}$ $\mathrm{O}_{2} / \mathrm{L} /$ month, irrespective of the period of oxygenation, resulted in low overall quality scores.

\section{Characteristics of the wines from 2004}

The phenolic composition of the 2004 wine was not affected significantly by the modified oxygenation protocol, except for the gallic acid and total flavan-3-ol content, which was significantly lower and higher than that of the control wine respectively (Fig. $6 \mathrm{~A}$ to $\mathrm{E}$ ). No significant difference in TAC was observed between the control and oxygenated wine (Fig. 6 F). The oxygenation treatment gave rise to wine with significantly higher $h^{*}$ and $b^{*}$ values than the control wine (Fig. 6G). The berry/plum intensity scores of the wines were significantly lower when using the oxygenation treatment (Fig. 6H).

\section{DISCUSSION}

Oxygenation is expected to facilitate direct and acetaldehydemediated anthocyanin-flavan-3-ol condensation reactions, as is the case for oak maturation. Pyranoanthocyanins may also be a product when oxygen is present, as the formation of most of these compounds requires an oxidation step (Monagas et al., 2005).

The formation of anthocyanin-derived pigments would therefore explain the substantial decrease in the content of all monomeric anthocyanins, $(+)$-catechin and procyanidin B1 in the wines after oxygenation. More pronounced changes occurred at the higher oxygenation level, as would be expected. At the same time, the polymeric anthocyanin content $(\mathrm{pH}$ shift) increased moderately, although the coloured polymer content (HPLC) showed a slightly different trend, with an increase only at the higher oxygenation level. The difference in trends is probably due to differences in the principles of the analytical methods used. The coloured polymer (HPLC) measurement only included polymers of five or more subunits (Peng et al., 2002), while some smaller oligomers may be included in the $\mathrm{pH}$ shift measurement due to their $\mathrm{pH}$ dependence (Escribano-Bailón et al., 2001). An increased concentration of sulphur dioxide-resistant pigments, i.e. polymers, and a decreased concentration of monomeric anthocyanins occurred when micro-oxygenation was used at different stages in the vinification process (Castellari et al., 1998; Castellari et al., 2000; Atanasova et al., 2002; Du Toit et al., 2006). Oxidative degradation of monomeric anthocyanins may also occur, especially at the high oxygenation level.

Previously, flavonols and hydroxycinnamic acids were shown to decrease when Sangiovese wines were oxygenated to saturation every month for six months (Castellari et al., 2000). In the present study, similar evidence of oxidative degradation was observed for flavonols and caffeic acid. Oxygenation caused a small but significant increase in the gallic acid content of wine over time, due to the hydrolysis of galloylated flavan-3-ols releasing gallic acid (Singleton \& Trousdale, 1983). Castellari et al. (2000), however, observed a decrease in gallic acid when a Sangiovese wine was oxygenated to saturation every month for six months. The total phenol content decreased only slightly, contrary to the HPLC-quantified monomers, and this was attributed to the reaction products still having reactivity in the Folin-Ciocalteau assay. A decrease in total phenol content was also observed after the oxygenation of a Sangiovese red wine (Castellari et al., 2000).

The oxygenation treatments were detrimental to the $\mathrm{TAC}_{\mathrm{M}}$ of the wines. Both monomeric compounds (represented by $\mathrm{TAC}_{\mathrm{CAL}}$ ) and unknown compounds (estimated by $\mathrm{TAC}_{\mathrm{R}}$ ) contributed to the de- 

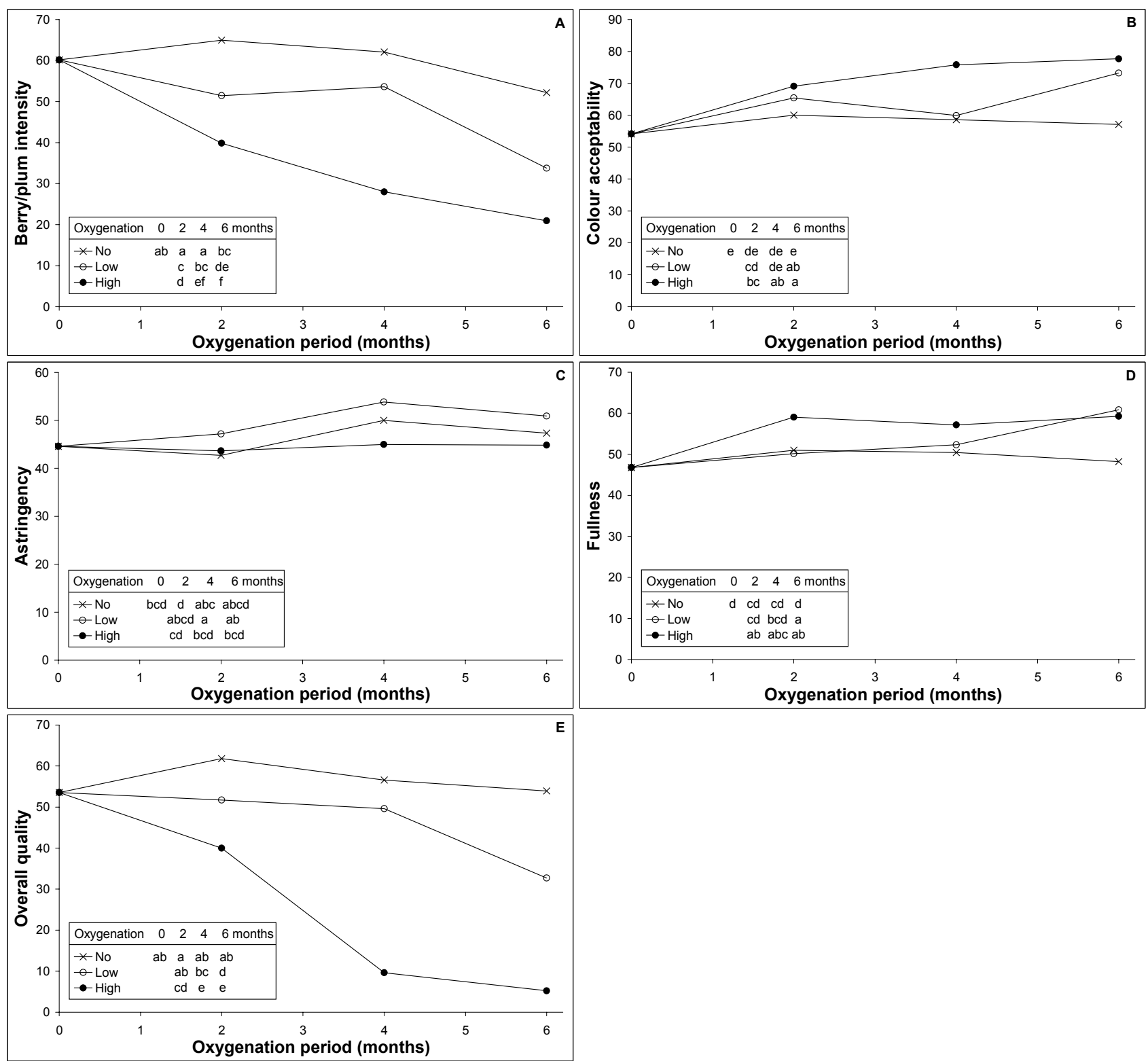

FIGURE 5

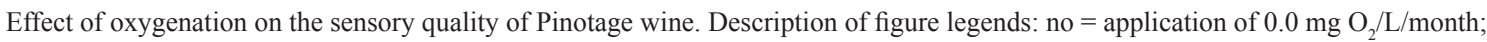
low $=$ application of $2.5 \mathrm{mg} \mathrm{O} / \mathrm{L} / \mathrm{month}$; high = application of $5.0 \mathrm{mg} \mathrm{O}_{2} / \mathrm{L} / \mathrm{month}$. Different letters denote significant differences $(\mathrm{p} \leq 0.05)$.

crease in $\mathrm{TAC}_{\mathrm{M}}$. The more pronounced decrease in the $\mathrm{TAC}_{\mathrm{CAL}}$ of wines subjected to longer oxygenation periods or the higher oxygen dosage is attributed to greater losses of most monomeric phenolic compounds, despite the increased concentration of gallic acid. Decreased concentrations of unknown antioxidant compounds could also play a role. Furthermore, the formation of anthocyanin-derived pigments and their contribution to the $\mathrm{TAC}_{\mathrm{M}}$ do not seem to compensate for the losses of monomeric and unknown compounds from the oxygenated wine.

The decrease in colour saturation $\left(C^{*}\right)$ and $a^{*}$ values of the wine with oxygenation is attributed to a decrease in monomeric anthocyanin content, especially since only a small increase in polymeric anthocyanin content was observed for some treatments. Decreased concentrations of co-pigment factors, such as $(+)$-catechin, procyanidin B1 and all individual flavonols, would also have contributed to the decrease in wine $C^{*}$ and $a^{*}$ values (Gonnet, 1999). Atanasova et al. (2002) reported a decrease in colour density (sum of absorbances at 420, 520 and $620 \mathrm{~nm}$ ) over time, although this was less severe for a micro-oxygenated wine than for the control wine. Some authors (Castellari et al., 2000; Du Toit et al., 2006), however, observed an increase in colour density with continuous micro-oxygenation or oxygenation in discrete doses.

Oxygenation changed the hue $\left(h^{*}\right)$ from an initial magenta-red to pure red in the direction of orange-red, with a subsequent change back to magenta-red. It seems that the first phase of oxygenation is characterised by the formation of orange-red pyranoanthocyanins (Fulcrand et al., 1996; Fulcrand et al., 1998), while the second phase corresponds to the formation of purple acetaldehydemediated anthocyanin-flavan-3-ol condensation products (Tim- 

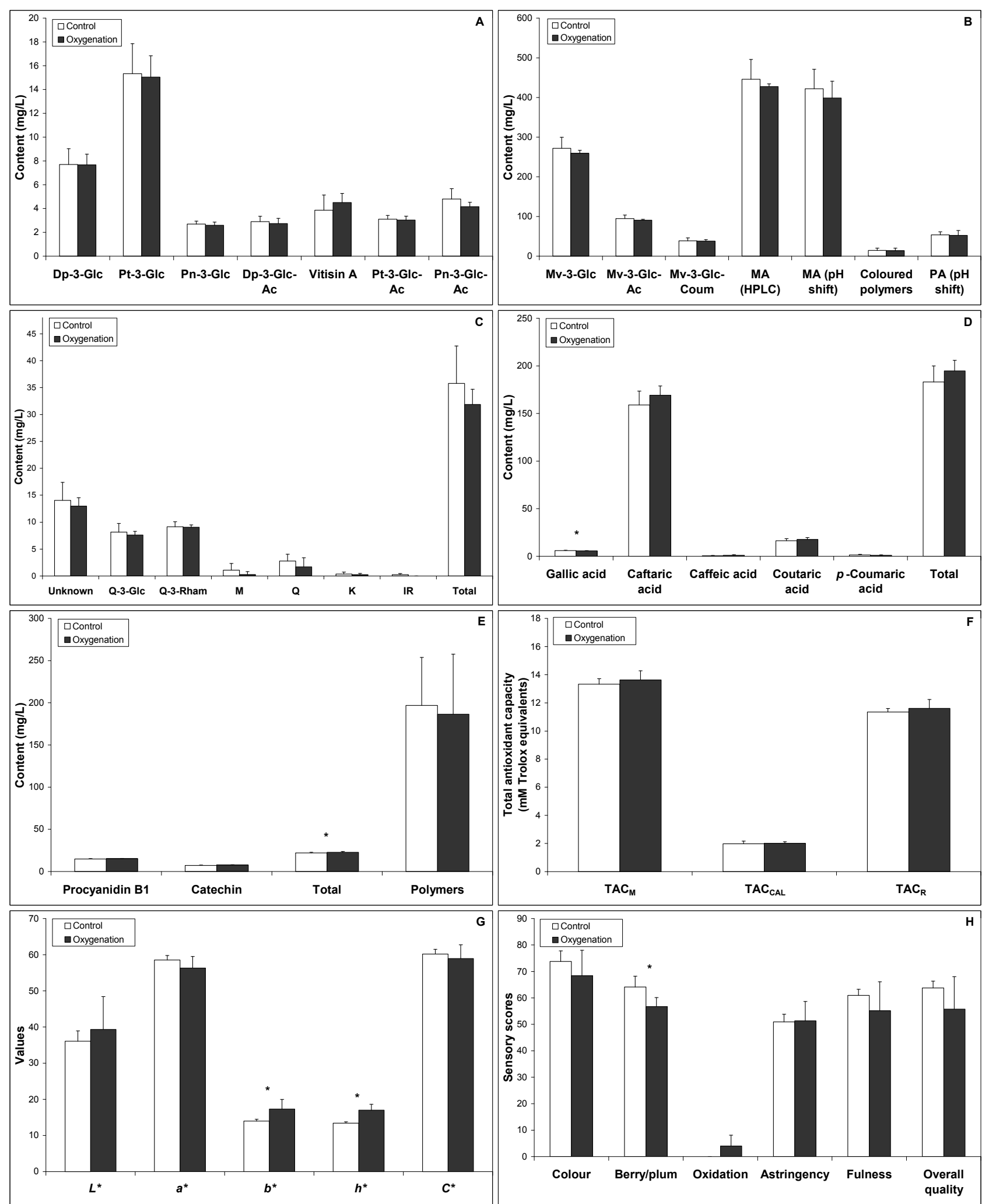

FIGURE 6

Effect of oxygenation $(1.0 \mathrm{mg} \mathrm{O} / \mathrm{L}$ in discrete doses every two weeks for two months) on the (A) + (B) anthocyanin content, (C) flavonol content, (D) phenolic acid content, (E) flavan-3-ol content, (F) total antioxidant capacity (TAC), (G) objective colour measurements and (H) sensory scores of Pinotage wine [* significant differences $(\mathrm{p} \leq 0.05) ; a^{*}=$ red/green chromaticity; $b^{*}=$ yellow/blue chromaticity; $C^{*}=$ chroma; $\mathrm{Dp}=$ delphinidin; Gal = galactoside; Glc = glucoside; Glc-Ac = acetylglucoside; Glc-Coum $=p$-coumaroylglucoside; $h^{*}=$ hue angle $\left(^{\circ}\right) ; \mathrm{IR}=$ isorhamnetin; $\mathrm{K}=$ kaempferol; $L^{*}=$ lightness; $\mathrm{M}=$ myricetin; $\mathrm{MA}=$ monomeric anthocyanins; $\mathrm{Mv}=$ malvidin; $\mathrm{PA}=$ polymeric anthocyanins; $\mathrm{Pn}=$ peonidin; $\mathrm{Pt}=$ petunidin; $\mathrm{Q}=$ quercetin; $\mathrm{Rham}=$ rhamnoside $]$. 
berlake \& Bridle, 1976; Rivas-Gonzalo et al., 1995). The trend for the content of vitisin A (a pyranoanthocyanin) supports this conclusion. The formation of brown polymers during the oxidative degradation of flavonoids would contribute to a hue change towards orange-red, but in this case the formation of purple-red ethyl-linked pigments seems to dominate. A similar trend to that observed in this study was also noted for the hue of a Cabernet Sauvignon wine micro-oxygenated $(1.5 \mathrm{mg} \mathrm{O} / \mathrm{L} / \mathrm{month}$ and 3.0 $\mathrm{mg} \mathrm{O}_{2} / \mathrm{L} /$ month) over 15 weeks (Du Toit et al., 2006).

The colour of the wine also became darker (lower $L^{*}$ ) with oxygenation, which resulted in higher colour acceptability scores during the sensory evaluation. However, this trend cannot be fully explained by the changes in phenolic composition, due to a variety of confounding factors. Complex changes in the pigment content and composition took place during oxygenation. A large percentage of anthocyanins in young wines are associated with tannins in the colourless flavene forms, which become red after oxidation (Liao et al., 1992). Brown polymers, for instance, contribute less to the wine $C^{*}$ than the original anthocyanins, but contribute to the darkening of the wine (lower $L^{*}$ ). This is the case especially when wines are exposed to large quantities of oxygen.

It is clear that $5.0 \mathrm{mg} \mathrm{O}_{2} / \mathrm{L} /$ month was severely detrimental to the quality of this Pinotage wine, especially with regard to berry/ plum intensity and overall quality. However, a lower dosage given for a short time can be beneficial in terms of increased colour acceptability and fullness. Sensory astringency scores, mainly associated with the polymer content (Vidal et al., 2004), did not change during oxygenation, despite modestly increased coloured polymer (HPLC) and polymeric anthocyanin ( $\mathrm{pH}$ shift) content for some treatments. The method of oxygen application can possibly affect the sensory quality. Continuous application of oxygen at very low quantities may have better results than application in discrete doses, although good results were obtained by Castellari et al. (2000) for oxygenation using discrete doses. In a previous study (Du Toit et al., 2006), continuous micro-oxygenation at levels of $1.5 \mathrm{mg} \mathrm{O}_{2} / \mathrm{L} /$ month and $3.0 \mathrm{mg} \mathrm{O} / \mathrm{L} /$ month for 15 weeks produced Cabernet Sauvignon wines that were preferred by a sensory panel over those produced from the control treatments. It is very important to note that the optimal oxygenation rate and time will be subject to the initial composition of the specific wine, especially in terms of tannins and anthocyanins, and the desired outcome. Monitoring of the dissolved oxygen, free sulphur dioxide, monomeric anthocyanins, colour and sensory properties of wine during the oxygenation period is advocated to avoid overoxygenation and to achieve the desired effect (Lemaire, 2003).

Results obtained for the oxygenated wine from 2004 (1 mg O/L every two weeks for two months) are in contrast to the trends observed for the wines from 2003 when higher oxygen doses were used $\left(2.5 \mathrm{mg} \mathrm{O}_{2} / \mathrm{L} /\right.$ month and $5 \mathrm{mg} \mathrm{O} / \mathrm{L} /$ month every month for two, four and six months). As a result of the phenolic composition of the oxygenated wine from 2004 being similar to that of the control wine, no significant differences in $\mathrm{TAC}_{\mathrm{M}}$ and $\mathrm{TAC}_{\mathrm{CAL}}$ or the contribution of any phenolic group to the $\mathrm{TAC}_{\mathrm{CAL}}$ were observed between the oxygenated and control wines, in contrast to the results for the wines from 2003. The oxygenated wine presented a magenta-red colour, closer to red than the hue of the control wine, due to the higher $b^{*}$, as was also observed for all the oxygenated wines in 2003 . These objective colour parameter trends did not re- sult in lower colour-acceptability scores for the oxygenated wines compared to the control wine, in contrast with the results for the 2003 wines. Although the phenolic content and TAC of the wines from 2004 were not affected, lower berry/plum intensity was still observed. However, the overall quality scores were unaffected by the modified oxygenation protocol.

\section{CONCLUSIONS}

Oxygenation showed potential for producing Pinotage wines with good colour and sensory quality. Care should be taken not to overoxidise the wine, as detrimental effects on sensory quality, phenolic content and the TAC of Pinotage wines were observed for some treatments. A low oxygen dose/short time protocol, however, improved the colour of the wine in 2003, although some loss of TAC was still observed. When using a modified oxygenation protocol with lower dosages at shorter time intervals, the overall sensory quality scores and TAC were not affected. Oxygenation should be investigated further to establish more favourable protocols that will allow improved sensory attributes, while retaining the TAC of the wine.

\section{ABBREVIATIONS}

$\mathrm{Ac}=$ acetate , Coum $=$ coumarate $; \mathrm{Gal}=$ galactoside $; \mathrm{Glc}=$ glucoside; Rham = rhamnoside; TAC $=$ total antioxidant capacity; $\mathrm{TAC}_{\mathrm{M}}=\mathrm{TAC}$ as measured; $\mathrm{TAC}_{\mathrm{CAL}}=\mathrm{TAC}$ as calculated from phenolic composition and TEAC values; $\mathrm{TAC}_{\mathrm{R}}=\mathrm{TAC}$ remaining after $\mathrm{TAC}_{\mathrm{CAL}}$ is subtracted from $\mathrm{TAC}_{\mathrm{M}} ; \mathrm{TE}=$ Trolox equivalents; $\mathrm{TEAC}=$ Trolox equivalent antioxidant capacity

\section{LITERATURE CITED}

Atanasova, V., Fulcrand, H., Cheynier, V. \& Moutounet, M., 2002. Effect of oxygenation on polyphenol changes occurring in the course of wine-making. Anal. Chim. Acta 458, 15-27.

Castellari, M., Arfelli, G. \& Amati, A., 1998. Evolution of phenolic compounds in red winemaking as affected by must oxygenation. Am. J. Enol. Vitic. 49, 91-94.

Castellari, M., Matricardi, L., Arfelli, G., Galassi, S. \& Amati, A., 2000. Level of single bioactive phenolics in red wine as a function of the oxygen supplied during storage. Food Chem. 69, 61-67.

De Beer, D., Joubert, E., Gelderblom, W.C.A. \& Manley, M., 2003. Antioxidant activity of South African red and white cultivar wines: free radical scavenging. J. Agric. Food Chem. 51, 902-909.

De Beer, D., Joubert, E., Gelderblom, W.C.A. \& Manley, M., 2005. Changes in the phenolic composition and antioxidant activity of Pinotage, Cabernet Sauvignon, Chardonnay and Chenin blanc wines during bottle ageing. S. Afr. J. Enol. Vitic. 26, 6-15.

De Beer, D., Joubert, E., Marais, J. \& Manley, M., 2006. Unravelling the total antioxidant capacity of Pinotage wines: contribution of phenolic compounds. J. Agric. Food Chem. 54, 2897-2905.

Du Toit, W.J., Lisjak, K., Marais, J. \& Du Toit, M., 2006. The effect of micro-oxygenation on the phenolic composition, quality and aerobic wine-spoilage microorganisms of different South African red wines. S. Afr. J. Enol. Vitic. 27, 57-67.

Escribano-Bailón, T., Álvarez-García, M., Rivas-Gonzalo, J.C., Heredia, F.J. \& Santos-Buelga, C., 2001. Color and stability of pigments derived from the acetaldehyde-mediated condensation between malvidin-3-O-glucoside and (+)-catechin. J. Agric. Food Chem. 49, 1213-1217.

Fulcrand, H., Cameira dos Santos, P.J., Sarni-Manchado, P., Cheynier, V. \& FavreBonvin, J., 1996. Structure of new anthocyanin-derived wine pigments. J. Chem. Soc., Perkin Trans. 1, 735-739.

Fulcrand, H., Benabdeljalil, C., Rigaud, J., Cheynier, V. \& Moutounet, M., 1998. A new class of wine pigments generated by reaction between pyruvic acid and grape anthocyanins. Phytochem. 47, 1401-1407.

Gonnet, J.-F., 1999. Colour effects of co-pigmentation of anthocyanins revisited. 2 . A colourimetric look at the solutions of cyanin co-pigmented by rutin using the CIELAB scale. Food Chem. 66, 387-394. 
Lemaire, T., 2003. Micro-oxygenation: fundamentals and facilities. Workshop at the 27th Viticulture and Enology Congress, Somerset West, South Africa.

Liao, H., Cai, Y. \& Haslam, E., 1992. Polyphenol interactions. Anthocyanins: copigmentation and colour changes in young red wines. J. Sci. Food Agric. 59, 299-305.

McMurrough, I. \& McDowell, I., 1978. Chromatographic separation and automated analysis of flavonols. Anal. Biochem. 91, 92-100.

Monagas, M., Bartolomé, B. \& Gomez-Cordoves, C., 2005. Updated knowledge about the presence of phenolic compounds in wine. Crit. Rev. Food Sci. Nutr. 45, 85-118.

Peng, Z., Iland, P., Oberholster, A., Sefton, M.A. \& Waters, E.J., 2002. Analysis of pigmented polymers in red wine by reversed phase HPLC. Aust. J. Grape Wine Res. 8, 70-75.

Re, R., Pellegrini, N., Proteggente, A., Pannala, A., Yang, M. \& Rice-Evans, C.A., 1999. Antioxidant activity applying an improved ABTS radical cation assay. Free Radical Biol. Med. 26, 1231-1237.

Ribéreau-Gayon, P. \& Stonestreet, E., 1965. Le dosage des anthocyanes dans les vins rouges. Bull. Soc. Chim. 9, 2649-2652.
Rivas-Gonzalo, J.C., Bravo-Haro, S. \& Santos-Buelga, C., 1995. Detection of compounds formed through the reaction of malvidin-3-monoglucoside and catechin in the presence of acetaldehyde. J. Agric. Food Chem. 43, 1444-1449.

Singleton, V.L. \& Rossi, J.R., 1965. Colourimetry of total phenols with phosphomolybdic-phosphotungstic acid reagents. Am. J. Enol. Vitic. 16, 144-158.

Singleton, V.L. \& Trousdale, E., 1983. White wine phenolics: varietal and processing differences as shown by HPLC. Am. J. Enol. Vitic. 34, 27-34.

Singleton, V.L., 1987. Oxygen with phenols and related reactions in musts, wines, and model systems: observations and practical implications. Am. J. Enol. Vitic. $38,69-77$.

Timberlake, C.F. \& Bridle, P., 1976. Interactions between anthocyanins, phenolic compounds, and acetaldehyde and their significance in red wines. Am. J. Enol. Vitic. 27, 97-105

Vidal, S., Francis, L., Noble, A.C., Kwiatkowski, M., Cheynier, V. \& Waters, E., 2004. Taste and mouth-feel properties of different types of tannin-like polyphenolic compounds and anthocyanins in wine. Anal. Chim. Acta 513, 57-65.

Wildenradt, H.L. \& Singleton, V.L., 1974. The production of aldehydes as a result of oxidation of polyphenolic compounds and its relation to wine ageing. Am. J. Enol. Vitic. 25, 119-126. 